\title{
Efecto del extracto hidroalcohólico de Eucalyptus globulus L. sobre Staphylococcus aureus
}

\author{
Judith Alvarado-Aguilar 1,a, Víctor Vásquez-Montenegro ${ }^{1, a}$, Martha Vergara-Espinoza ${ }^{1, b}$ \\ Cinthya Santa Cruz-López ${ }^{1, b}$
}

\section{RESUMEN}

Objetivos. Evaluar el efecto inhibitorio in vitro del extracto hidroalcohólico de Eucalyptus globulus L. sobre cepas de Staphylococcus aureus aislados de vacas con mastitis. Materiales y métodos. La investigación es de tipo experimental y se utilizó el diseño de estímulo creciente a diferentes concentraciones y un grupo control, para lo cual se evaluó el extracto que se obtuvo de hojas secas con etanol al $80 \%$ (v/v) y se emplearon concentraciones de 100, 200, 300, 400 y $500 \mathrm{mg} / \mathrm{ml}$ en 10 cepas de S. aureus (S1-S10). El efecto inhibitorio se evaluó por el método de difusión en agar de Kirby-Bauer. Resultados. Se obtuvo que la cepa más sensible al extracto hidroalcohólico fue SA2, mientras que SA10 mostró la mayor resistencia. Así mismo, la concentración de $500 \mathrm{mg} / \mathrm{ml}$ fue la que tuvo mayor actividad inhibitoria con un halo promedio de $19,29 \mathrm{~mm}$ en la totalidad de las cepas evaluadas. Ambas variables en estudio mostraron diferencias significativas. Conclusión. El efecto inhibitorio del extracto hidroalcohólico de E. globulus L. sobre cepas de $S$. aureus es directamente proporcional a su concentración y varía ligeramente entre las cepas evaluadas.

Palabras clave: Eucalyptus globulus L., Staphylococcus aureus, Mastitis (Fuente: DeCS-BIREME).

\section{Effect of Eucalyptus globulus L. hydroalcoholic extract on Staphylococcus aureus}

\section{ABSTRACT}

Objectives. To evaluate Eucalyptus globulus L.' hydroalcoholic extract in vitro inhibitory effect over isolated Staphylococcus aureus' strains from dairy cows with mastitis. Materials and methods: This is an experimental research, the design consisted of increasing stimulus at different concentrations, a control group was used; the extract obtained from dry leaves with $80 \%$ ethanol $(\mathrm{v} / \mathrm{v})$ was put on trial and 100, 200, 300,400 and $500 \mathrm{mg} / \mathrm{ml}$ concentrations were employed in $10 \mathrm{~S}$. aureus' strains (S1-S10). The inhibitory effect was assessed by the KIRBY BAUER agar diffusion method. Results: The most sensitive strain to the hydroalcoholic extract was SA2, while SA10 showed highest resistance. Likewise, it was the $500 \mathrm{mg} / \mathrm{ml}$ concentration the one with highest inhibitory activity, with an average halo of $19.29 \mathrm{~mm}$ in all the evaluated strains. Both studied variables showed significant variations. Conclusion: The E. globulus L.'s hydroalcoholic extract inhibitory effect over S. aureus strains is directly proportional to its concentration and slightly differs among the evaluated strains.

Key words: Eucalyptus globulus, Staphylococcus aureus, Mastitis (Source: MeSH-NLM).

\footnotetext{
${ }^{1}$ Facultad de Ciencias Biológicas, Universidad Nacional Pedro Ruiz Gallo, Lambayeque, Perú

2 Universidad Nacional de Jaén, Cajamarca, Perú.

a Biólogo Microbiólogo.

b Biólogo Microbiólogo, doctora en ciencias.

b Biólogo Microbiólogo, maestra en microbiología clínica. 


\section{INTRODUCCIÓN}

La mastitis bovina es una afección que se caracteriza por la inflamación de las glándulas mamarias, siendo considerada un problema de gran interés en la ganadería lechera a nivel mundial y el sector lácteo (1). Debido a que ocasiona una menor producción de leche; originando elevados gastos en el tratamiento de la enfermedad, pérdidas por descarte y muertes de los animales ${ }^{(2,3)}$.

Los microorganismos causantes de alrededor del $90 \%$ de los casos clínicos y subclínicos de mastitis son Staphylococcus spp., Streptococcus spp., y algunas bacterias Gram negativas. Siendo el Staphylococcus aureus, el principal patógeno causante de la mastitis en hatos lecheros del Perú ${ }^{(4,5)}$, ya que los estafilococos están relacionados principalmente con la mastitis subclínica, logrando colonizar la piel y el canal del pezón, lo que predispone a la infección intramamaria (1).

Cabe resaltar que, $S$. aureus es un microorganismo que se encuentra ampliamente diseminado en el ambiente y además está relacionado con problemas de foliculitis e intoxicaciones alimentarias. Así también, endocarditis, neumonía y síndrome del shock tóxico, debido a las características particulares de virulencia y resistencia frente a los antibióticos que posee. La resistencia de $S$. aureus puede producirse mediante selección natural, a través de mutaciones y, por el uso excesivo de antibióticos ${ }^{(6)}$.

En el departamento de Lambayeque se ha reportado que los microorganismos que poseen mayor relación con el desarrollo de la mastitis son S. aureus en un 39,04 \%, Staphylococcus epidermidis en $33,47 \%$, Staphylococcus spp. en 7,17 \%, Streptococcus agalactiae en 6,37 \% y Escherichia coli solo en un $2,79 \%{ }^{(7)}$.

De modo que, el tratamiento antimicrobiano resulta ser la forma más utilizada para tratar la mastitis, sin embargo, el poder residual de algunos fármacos en la leche, constituye un gran riesgo para la producción de diversos derivados lácteos y la salud humana. Además, los primordiales problemas en su aplicación, están relacionados con los elevados costos para el productor y, la aparición de cepas bacterianas cada vez más resistentes a estos antibióticos ${ }^{(8)}$.

Por lo que, es necesario buscar alternativas terapéuticas para combatir la infección ocasionada por este microorganismo, que presenten mayor eficacia, resulten de bajo costo, fácil aplicación y sin o con menores efectos colaterales que los medicamentos expendidos en el mercado. Para lo cual, se ha evaluado el efecto antibacteriano de especies vegetales que pudieran brindar una opción para el tratamiento de la mastitis ${ }^{(1,8,9,10)}$. Entre ellas tenemos al Eucalyptus globulus L., una especie que pertenece a la familia Myrtaceae, en cuyas hojas se encuentran principios activos como taninos, resinas, ácidos grasos, aceites esenciales compuestos por eucaliptol en un $80 \%$, d-pineno, canfeno, aldehídos, ácidos fórmico y acético esterificados que lo convierten en un potente desinfectante natural ${ }^{(8)}$.

Por lo anteriormente expuesto, el estudio tuvo como objetivo determinar el efecto in vitro del extracto hidroalcohólico de E. globulus (eucalipto), a las concentraciones de $100,200,300,400$ y $500 \mathrm{mg} / \mathrm{ml}$, sobre 10 cepas de $S$. aureus aisladas de vacas con mastitis; considerando que es una afección que origina grandes pérdidas económicas y que puede alterar la calidad de los productos lácteos que son ingeridos por la población, además de contribuir al mejor estudio de la especie vegetal e incentivar investigaciones futuras que permitan evitar o minimizar los terribles efectos colaterales de los medicamentos convencionales que se utilizan para tratar esta enfermedad.

\section{MATERIAL Y MÉTODOS}

\section{Tipo y diseño de investigación}

La investigación es de tipo experimental y se utilizó el diseño de estímulo creciente, con diferentes concentraciones y un grupo control (11).

\section{Población y muestra}

La población y muestra estuvo constituida por 10 cepas de $S$. aureus aisladas de vacas con mastitis proporcionadas por la Facultad de Medicina Veterinaria de la UNPRG, incluyendo solo aquellas cepas bacterianas puras y que no fueron empleadas con anterioridad en otras investigaciones.

\section{Técnicas e instrumentos de recolección de datos}

\section{Preparación del extracto hidroalcohólico}

Para la preparación del extracto alcohólico de E. globulus., se emplearon $3 \mathrm{Kg}$ de hojas de eucalipto, previamente lavadas y desinfectadas; posteriormente se secaron a temperatura ambiente y sin tener contacto directo con la luz solar. Las hojas secas fueron trituradas en un mortero hasta obtener un polvo fino de masa seca, luego se colocó en un vaso de precipitación, $50 \mathrm{~g}$ de la masa seca con $500 \mathrm{~mL}$ de etanol al $80 \%$ y se dejó macerar durante 7 días a temperatura ambiente. Transcurrido el tiempo, se realizó el filtrado del macerado y se distribuyó en placas estériles para favorecer la evaporación total del alcohol del extracto líquido. El extracto crudo obtenido fue colocado en un frasco estéril color ámbar y se almacenó en refrigeración, protegiéndolo de la luz solar hasta su utilización ${ }^{(12)}$. Para obtener la concentración de $100 \mathrm{mg} / \mathrm{ml}$, se colocó en un recipiente estéril, $1 \mathrm{~g}$ del extracto seco y se agregó $10 \mathrm{~mL}$ de etanol al $40 \%$, similar metodología se empleó para preparar el extracto a las concentraciones de $200,300,400$ y $500 \mathrm{mg} / \mathrm{ml}$.

Método de difusión en agar 
Se reactivaron las cepas de $S$. aureus (previamente identificadas mediante pruebas bioquímicas) en $5 \mathrm{ml}$ de caldo nutritivo y se incubaron a $37^{\circ} \mathrm{C}$ durante 4 a 6 horas, para alcanzar una turbidez similar al tubo $\mathrm{N}^{\circ} 0.5$ del nefelómetro de Mc Farland (1,5 x $108 \mathrm{ufc} / \mathrm{ml})$. Los discos de sensibilidad se elaboraron con papel Whatman $\mathrm{N}^{\circ} 01$ y tenían un diámetro de $5 \mathrm{~mm}$, se colocaron en viales y se esterilizaron en autoclave, luego se dejaron secar en horno durante 24 horas a $60{ }^{\circ} \mathrm{C}$. Posteriormente, los discos de sensibilidad fueron humedecidos con las concentraciones del extracto y se les dejó reposar por 5 minutos para luego realizar la prueba de susceptibilidad antimicrobiana

Se realizó la siembra superficial del inóculo bacteriano embebido en un hisopo estéril sobre placas con agar Müller Hinton, (sometidas previamente a control de esterilidad durante 24 horas a $37^{\circ} \mathrm{C}$ ) y después de 5 minutos, se colocaron los discos impregnados con extracto hidroalcohólico a las diferentes concentraciones evaluadas, separados entre sí por una distancia aproximada de 15-20 mm. Además, se colocó un disco embebido en etanol al $40 \%$, como control negativo. Seguidamente se incubaron las placas a $37{ }^{\circ} \mathrm{C}$ durante 24 horas y finalmente se midieron los halos de inhibición con una regla común con escala en milímetros, registrando la medida para cada una de las cepas ${ }^{(13)}$.

Por último, como técnica de recolección de datos se utilizó la observación estructurada de las variables a evaluar. Además, como instrumento de recolección de datos se empleó una lista de control, donde se registraron los eventos y sus características durante el desarrollo del experimento.

\section{Análisis de datos}

Para el análisis estadístico de los datos se utilizó el programa Microsoft Office Excel® 2016. Los datos obtenidos fueron tratados estadísticamente mediante el Análisis de Varianza, con la finalidad de determinar si la inhibición bacteriana era por efecto de la concentración del extracto hidroalcohólico del eucalipto o del tipo de cepa empleado y los datos se complementaron con la Prueba de Tukey, para determinar el efecto de las concentraciones de 100, $200,300,400$ y 500 mg/ml del extracto hidroalcohólico eucalipto sobre las cepas de $S$. aureus.

\section{RESULTADOS}

En la investigación, se determinó el efecto del extracto hidroalcohólico de E. globulus (eucalipto) a concentraciones de $100,200,300,400$ y $500 \mathrm{mg} / \mathrm{ml}$ sobre 10 cepas de $S$. aureus (SA1-SA10) mediante la prueba de susceptibilidad antibiótica por difusión en agar, observándose un aumento sostenido en los diámetros de los halos inhibitorios entre las diferentes concentraciones evaluadas, respecto al diámetro obtenido con el control. Siendo el halo de inhibición de 23,33 mm en las cepas SA4 y SA6 para la concentración de $500 \mathrm{mg} / \mathrm{ml}$, el mayor diámetro obtenido (Tabla 01).

Tabla 1. Diámetro de halos inhibitorios obtenidos del extracto hidroalcohólico de Eucalyptus globulus L. (eucalipto) a las concentraciones de 100, $200,300,400$ y $500 \mathrm{mg} / \mathrm{ml}$ sobre 10 cepas de $S$. aureus.

\begin{tabular}{|c|c|c|c|c|c|c|c|c|c|c|}
\hline \multirow{2}{*}{$\begin{array}{l}\text { Concentración del } \\
\text { extracto } \\
(\mathrm{mg} / \mathrm{ml})\end{array}$} & \multicolumn{10}{|c|}{ Halos de inhibición (mm) } \\
\hline & SA1 & SA2 & SA3 & SA4 & SA5 & SA6 & SA7 & SA8 & SA9 & SA10 \\
\hline 100 & 15,67 & 16,67 & 15,00 & 16,33 & 14,33 & 15,67 & 15,00 & 14,67 & 14,67 & 14,00 \\
\hline 200 & 17,00 & 18,33 & 17,61 & 17,67 & 16,00 & 16,67 & 16,00 & 15,67 & 15,67 & 15,00 \\
\hline 300 & 17,67 & 18,67 & 17,61 & 18,67 & 17,00 & 17,67 & 17,00 & 16,33 & 16,67 & 15,67 \\
\hline 400 & 18,33 & 19,67 & 19,00 & 19,00 & 18,00 & 18,67 & 18,00 & 18,00 & 17,67 & 16,67 \\
\hline 500 & 20,00 & 19,33 & 19,33 & 20,33 & 20,00 & 20,33 & 19,67 & 18,67 & 18,67 & 17,67 \\
\hline
\end{tabular}

Además, mediante el análisis de varianza expuesto en el Gráfico 1, se evidencia las diferencias significativas entre los promedios de los halos de inhibición del crecimiento bacteriano y, en el gráfico 2, la variación del efecto producido por las distintas concentraciones del extracto hidroalcohólico y el tipo de cepa. Sin embargo, la interacción de dichos factores no presentó diferencias significativas. La prueba de significancia realizada evidenció la dependencia en los promedios de los halos inhibitorios de acuerdo a las fuentes de variación del análisis. 


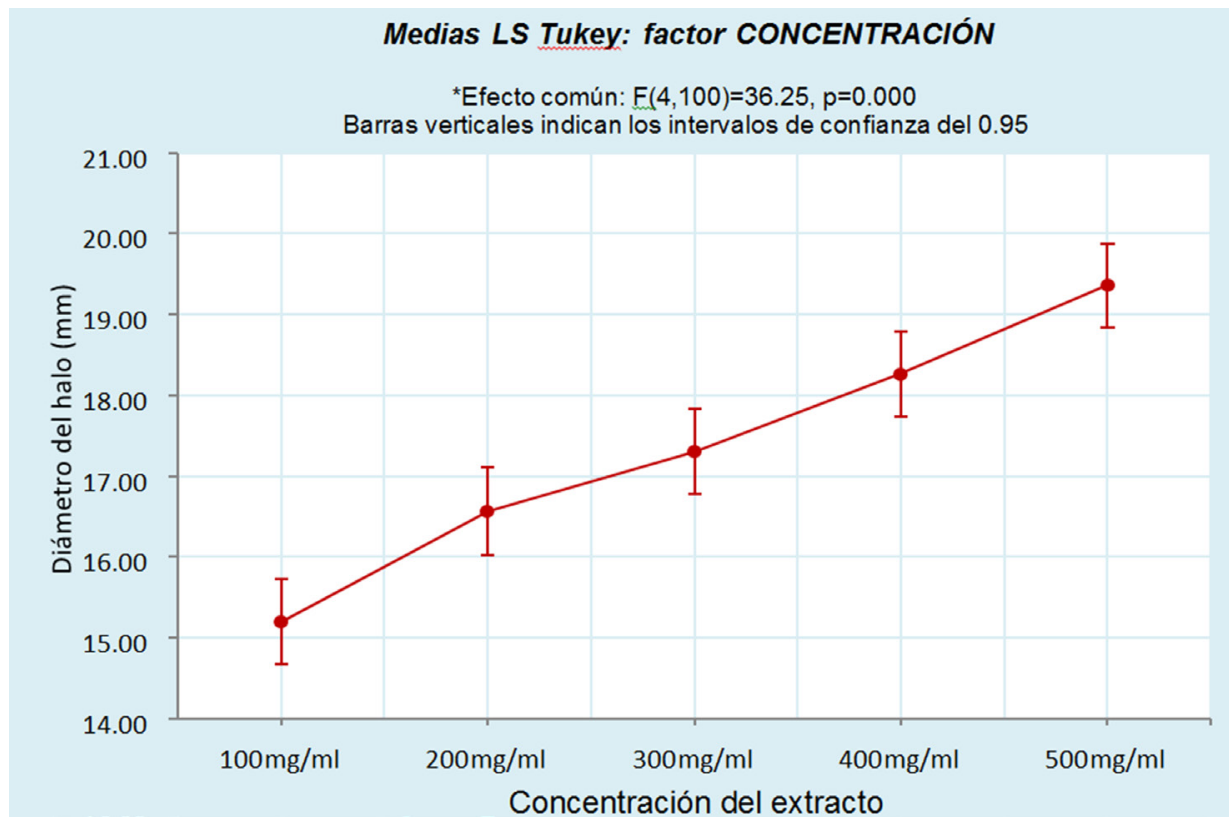

Tabla 1. Análisis de varianza del efecto in vitro del extracto hidroalcohólico de Eucalyptus globulus L. (eucalipto) a las concentraciones de $100,200,300,400$ y $500 \mathrm{mg} / \mathrm{ml}$.

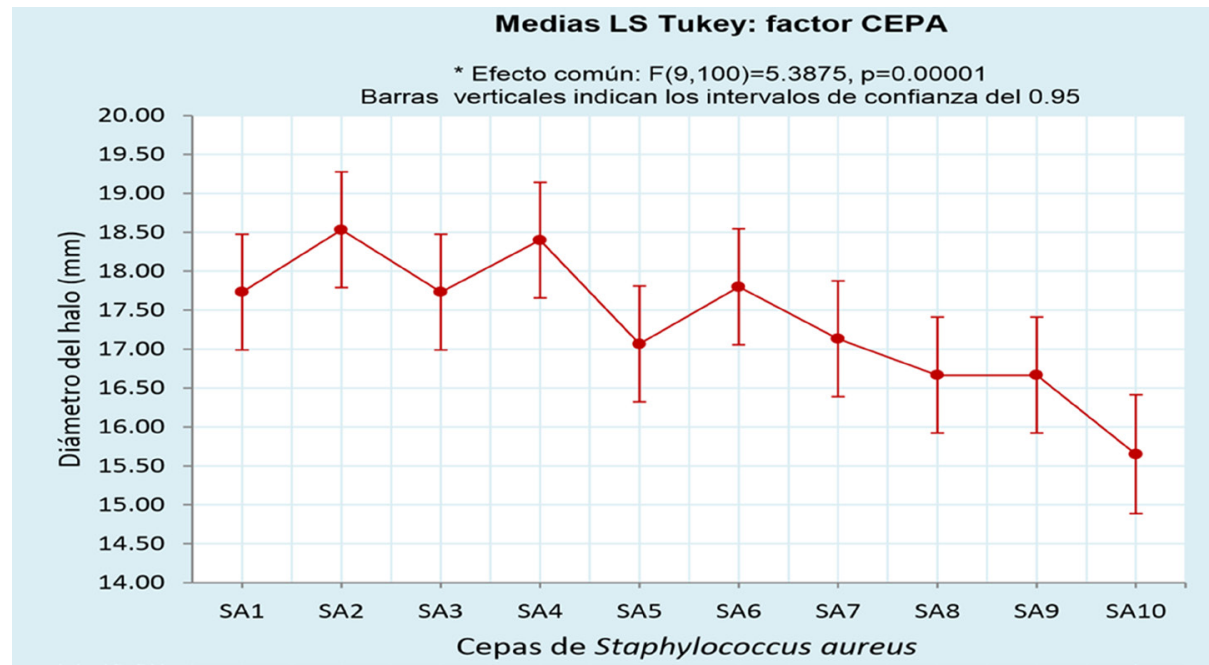

Grafica 2. Análisis de Varianza del efecto in vitro del extracto hidroalcohólico Eucalyptus globulus L. (eucalipto) sobre 10 cepas bacterianas de Staphylococcus aureus. 
La tabla 2, muestra la diferencia significativa entre las concentraciones del extracto hidroalcohólico, siendo estas, directamente proporcional al promedio de halo de inhibición. Considerando que la concentración de $500 \mathrm{mg} / \mathrm{ml}$ produjo el mayor halo de inhibición con un promedio de 19,29 mm.

Tabla 02: Prueba de significancia de Tukey de los promedios de halos de inhibición ocasionados por el efecto del extracto hidroalcohólico de Eucalyptus globulus L. (eucalipto) a las concentraciones de 100, 200, 300, 400 y 500 mg/ $\mathrm{ml}$ sobre 10 cepas de Staphyloccocus aureus.

\begin{tabular}{llll} 
Concentración $(\mathrm{mg} / \mathrm{ml})$ & Promedio de halo & $\begin{array}{l}\text { Nivel de significa- } \\
\text { ción* }\end{array}$ \\
\hline 100 & 15,200 & a & \\
200 & 16,621 & b & \\
300 & 17,300 & b & C \\
400 & 18,267 & C & d \\
500 & 19,290 & & \\
\hline
\end{tabular}

${ }^{*}$ ) Letras iguales: no existe diferencia; letras diferentes: existe diferencia

En la Tabla 03, se observan las diferencias entre cada una de las cepas bacterianas empleadas de acuerdo al halo de inhibición producido por las diferentes concentraciones del extracto hidroalcohólico, siendo la cepa SA2 la de mayor sensibilidad, obteniendo un halo de inhibición promedio de $18,53 \mathrm{~mm}$.

Tabla 3: Prueba de significancia de Tukey, de los promedios de halos de inhibición por efecto del extracto hidroalcohólico de Eucalyptus globulus L. (eucalipto) sobre cepas bacterianas de Staphylococcus aureus.

\begin{tabular}{ccccc} 
Cepas & Media & \multicolumn{3}{c}{$\begin{array}{c}\text { Nivel de } \\
\text { significancia } \\
\left({ }^{*}\right)\end{array}$} \\
SA10 & 15,80 & a & b & \\
SA9 & 16,67 & a & b & \\
SA8 & 16,67 & a & b & \\
SA5 & 17,07 & a & b & c \\
SA7 & 17,13 & a & b & c \\
SA1 & 17,73 & & b & c \\
SA3 & 17,73 & & b & c \\
SA6 & 17,80 & & & $c$ \\
SA4 & 18,40 & & & $c$ \\
SA2 & 18,53 & & & $c$ \\
\hline
\end{tabular}

$\left.{ }^{*}\right)$ Letras iguales: no existe diferencia; letras diferentes: existe diferencia.

\section{DISCUSIÓN}

Se evaluaron concentraciones de 100, 200, 300, 400 y 500 $\mathrm{mg} / \mathrm{ml}$ del extracto hidroalcohólico de E. globulus (eucalipto) sobre 10 cepas de S. aureus (SA1-SA10) aisladas de vacas con mastitis. Encontrando un aumento considerable en el diámetro del halo de inhibición, en las diferentes concentraciones evaluadas, respecto al control. Obteniendo un halo de inhibición de 23,33 mm al exponer las cepas a la concentración de $500 \mathrm{mg} / \mathrm{ml}$.

Cabe resaltar que, la presencia de principios activos como los taninos, resinas, ácidos grasos, fenoles, flavonoides, los alcoholes etílico y amílico, los ácidos fórmico y acético esterificados ${ }^{{ }^{9}, 14}$ en las hojas del eucalipto, estarían implicados en el efecto bactericida de la planta, ya que pueden alterar la permeabilidad de la pared y membrana celular, lo que ocasiona lisis bacteriana ${ }^{(14)}$. Del mismo modo, los solventes polares, como el etanol y agua, tienen la capacidad de extraer flavonoides hidroxilados ${ }^{(15)}$, que se distribuyen fácilmente por las paredes celulares con bajo contenido de lipopolisacáridos, como las paredes de las bacterias Gram positivas y, que resultan tóxicas para la célula ${ }^{(16,17)}$.

Los resultados obtenidos en el estudio, concuerdan con los encontrados por Liu et al., quienes reportaron que el extracto a base de alcohol-acetona de Eucalyptus sp., inhibe el desarrollo de bacterias Gram positivas ${ }^{(18)}$. Así también, otros investigadores reportaron que los extractos naturales de hojas y tallos de E. globulus, Bacaris trimera, Salvia officinalis, Peumus boldus y Tagetes minuta presentan mayor actividad antibacteriana contra microorganismos Gram positivos, como el $S$. aureus ${ }^{(19,20)}$.

Cabe resaltar que, las cepas de S. aureus (SA1-SA10) empleadas resultaron sensibles a la actividad del extracto hidroalcohólico, considerando la longitud del halo de inhibición encontrado. De manera que, la cepa SA2 presentó mayor sensibilidad, encontrándose un halo de inhibición de 18,53 mm de diámetro. Mientras que, la cepa SA10 alcanzó un halo de $15,80 \mathrm{~mm}$ de diámetro, siendo más resistente al efecto del extracto. Está marcada diferencia en el comportamiento de las cepas estaría relacionada a la producción de exopolisacáridos, como la cápsula, que sintetizan algunas especies de bacterias y, que evitan el paso de compuestos dañinos a las células (21,22). Así también, las mutaciones del material genético bacteriano que les confieren a las bacterias cambios en su estructura o su reacción a diversos compuestos químicos ${ }^{(23)}$.

En la presente investigación, el extracto hidroalcohólico de eucalipto a una concentración de $100 \mathrm{mg} / \mathrm{ml}$ indujo la aparición de halos de inhibición con un diámetro promedio de $15,2 \mathrm{~mm}$. Siendo superior al obtenido utilizando extractos etanólicos y metanólicos ${ }^{(9)}$. Debido a que tanto $E$. globulus, como los propóleos poseen compuestos como resinas, flavonoides, alcoholes, aceites volátiles y fenoles; pero que dichos compuestos, se pueden encontrar en mayor cantidad dentro de los extractos hidroalcohólicos, debido a que el agua logra incrementar el poder de extracción de numerosas sustancias con interés terapéutico (24). Para evaluar el efecto del alcohol sobre el crecimiento de $S$. aureus se embebió discos donde solo se añadió 
alcohol en lugar del extracto. El disco también fue colocado de forma independiente en una placa sembrada.

De manera que, se demostró el efecto inhibitorio del extracto hidroalcohólico a base de hojas secas de E. globulus. Al respecto Voigt et al ${ }^{24)}$, evidenciaron que existe una diferencia entre el efecto inhibitorio de extractos obtenidos de hojas secas y frescas, teniendo mayor eficacia el extracto obtenido a partir de estas últimas. Mientras que, Yáñez y Cuadro (14), reportaron mayor actividad antibacteriana sobre cepas de S. aureus utilizando aceites esenciales obtenidos de hojas secas de eucalipto. Estos resultados pueden atribuirse a que la acción bactericida del eucalipto está relacionada con el tipo de la especie, cantidad de los componentes químicos, condiciones del suelo, edad de espécimen vegetal, así como por variaciones genéticas ${ }^{(8,14)}$.

En tanto, el E. globulus ha sido sometido a diversos estudios para establecer su actividad antibacteriana, antimicótica, antiparasitaria, antiviral e insecticida ${ }^{(3)}$, pero ninguno de ellos orientado a infecciones que afectan a animales domésticos o de cría. No obstante, Alzamora et al. (3) y Yañes y Cuadro (14) han reportado actividad antibacteriana frente a $S$. aureus (de fuente ajena a bovinos). Los resultados obtenidos de las investigaciones científicas reafirman el uso popular de E. globulus y permiten orientar su uso para el tratamiento de enfermedades causadas por S. aureus, como la mastitis bovina.

Sin embargo, se hace necesario realizar bioensayos prospectivos, ya que existen muchas plantas y sus metabolitos secundarios que podrían emplearse como medicamentos alternativos, debido a que el creciente problema de la resistencia a los antibióticos se ha extendido al campo de la terapéutica veterinaria, por el uso indiscriminado de antibióticos y la adición en los concentrados empleados en la alimentación de animales, lo que ha originado que bacterias como $S$. aureus hayan adquirido cada vez mayor resistencia.

El estudio solo se realizó in vitro, por tanto, se considera de gran importancia evaluar la toxicidad del extracto, el extracto hidroalcohólico de E. globulus. Así también, evaluar diferentes tipos extractos de eucalipto que permitan monitorear el comportamiento de la planta frente a distintos aditivos, además de potenciar su efecto. Con la finalidad de evidenciar su potencial uso empírico, pudiéndose convertir en una opción de tratamiento más económica y siendo de gran utilidad para la población.

En conclusión, el extracto hidroalcohólico de E. globulus (eucalipto), tuvo efecto inhibitorio sobre las 10 cepas de $S$. aureus aisladas de vacas lecheras con mastitis, siendo directamente proporcional a la concentración del extracto. Además, la concentración con mayor efecto inhibitorio sobre S. aureus fue de $500 \mathrm{mg} / \mathrm{ml}$ con un halo promedio de 19,29 $\mathrm{mm}$ de diámetro en la totalidad de las cepas evaluadas.

\section{Financiación: Autofinanciado.}

\section{Conflicto de interés: Ninguno.}

Agradecimiento: a la Universidad Nacional Pedro Ruiz Gallo, que brindó el ambiente adecuado y equipo requerido para el procesamiento de las muestras biológicas. Además, a la Facultad de Medicina Veterinaria de dicha casa de estudios por brindar las 10 cepas de $S$. aureus.

\section{REFERENCIAS BIBLIOGRÁFICAS}

1. López V. Evaluación del efecto antibacteriano in vitro de seis especies de plantas de uso medicinal sobre bacterias causantes de mastitis en vacas lecheras. [Tesis para optar por el título profesional de Médico veterinario]. Guatemala: Facultad Medicina Veterinaria y Zootecnia de la Universidad San Carlos; 2009.

2. Quinn P, Markey B, Carter M, Donnelly W y Leonard F. Microbiología y enfermedades infecciosas veterinarias. 2a ed. España: Editorial Acribia. 2017.

3. Voigt F, Lambrecht C, Damé L, Silveira H y Hartwig C. Comparación de distintas extracciones hidroalcohólicas de plantas con indicativo etnográfico antiséptico/desinfectante. Rev Cubana Plant Med. 2011 16(3): 236-43.

4. De Oliveira AP, Watts JL, Salmon SA y Aarestrup FM. Antimicrobial susceptibility of Staphylococcus aureus isolated from bovine mastitis in Europe and the United States. J Dairy Sci. 2000; 83(4):855-62.

5. Camussonea CM y Calvinhoa LF. Factores de virulencia de Staphylococcus aureus asociados con infecciones mamarias en bovinos: relevancia y rol como agentes inmunógenos. Rev Argent Microbiol. 2013 45(2):119-30

6. Zendejas-Manzo GS, Avalos-Flores H, Soto-Padilla MY. Microbiología general de Staphylococcus aureus: Generalidades, patogenicidad y métodos de identificación. Rev Biomed. 2014; 25:129-43.

7. Vergara M, Delgado N, Albino G y Montenegro Z. Mastitis: Perspectiva de una infección. Centro de Investigación Facultad Medicina Veterinaria. Universidad Nacional Pedro Ruiz Gallo. Lambayeque; 2005.

8. Barreto G, Velásquez B y Rodríguez H. Evaluación in vitro de los extractos de Eucalyptus citriodora y Eucalyptus saligna como posibles antisépticos mamarios. Rev. Prod. Animal. 2006; 18 (2): 135-40.

9. Fonseca S, Torquato L, Alves D, Teixeira F y Soares A. Evaluación de plantas medicinales en el combate a mastitis bovina. Holos. 2009; 25 (4):96 - 102

10. Pinto M, De Faria J, Message D, Cassini S, Pereira C y Gioso M. Efecto de extractos de propóleos verdes sobre bacterias patógenas aisladas de la leche de vacas con mastitis. Braz. J. Vet. Res. Anim Sci. 2001; 38(6): 278-83.

11. Stracuzzi SP, Pestana FM. Metodología de la investigación cuantitativa. 2.a ed. Venezuela: FEDUPEL; 2006.

12. Barreto $G$ y Campal A. Efectos de extractos de Eucalyptus salignay Eucalyptus citriodora sobre la viabilidad y expresión fimbrial (K88 y CFA/I) de E. coli enterotoxigénica. Rev Prod Anim. 2001; 13(2): 67-75.

13. Kinsbruy D, Warner G y Seagel G. Manual de microbiología médica. 1.a ed. España: Edit. Orientación; 1991.

14. Yáñez $X$ y Cuadro $O$. Composición química y actividad antibacteriana del aceite esencial de las especies Eucalyptus globulus y $\mathrm{E}$. camaldulensis de tres zonas de Pamplona (Colombia). Rev de la Facultad de Ciencias Básicas. 2012; 1(10): 52-61.

15. Cartaya O y Reynaldo I. Flavonoides: Características químicas y aplicaciones. Cultivos Tropicales. 2001; 22(2): 5-14.

16. Takahashi T, Kokubo R y Sakaino M. Antimicrobial activities of eucalyptus leaf extracts and flavonoids from Eucalyptus maculata. Letters in Applied Microbiology. 2004; 39: 60-64

17. Domingo D Y López M. Plantas con acción antibacteriana. Rev Esp Quimioterap. 2003; 16(4):385-93.

18. Liu H, Lengua L, León G, La Torre C, Huapaya J y Chauca J. Evaluación de la actividad antibacteriana in vitro de los extractos de Caesalpinia spinosa "tara" y Eucalyptus sp. "eucalipto". [Tesis para optar por el título profesional de Médico cirujano]. Lambayeque: Facultad Medicina Humana de la Universidad San Martín de Porres; 2002.

19. Dame L, Wiest J, Silveira H, Souza L, De Toni L y Dos Santos J. Cinética da actividad antibacteriana in vitro de extractos naturales frente a microrganismos relacionados a la mastitis bovina. Ciencia Animal Brasileira. 2008; 1(9):161-169.

20.Salazar R, De la Torre B, Alanís L, Pérez LA y Waksman N. Evaluación de la actividad biológica de productos herbolarios comerciales. 
Medicina Universitaria. 2009; 11(44):156-164.

21. Koneman E, Winn W, Allen S, Janda W, Procop G, Woods G y Schreckenberger P. Color Atlas and Textbook of Diagnostic Microbiology.6a ed. USA: Ed. Lippincott Williams \&Wilkins; 2006.

22. Pahissa A. Infecciones producidas por Staphylococcus aureus. 1a ed. España: ICG Marge SL; 2009.

23. Echevarría- Zarate J, Iglesias - Quilca D. Estafilococo Meticilino resistente, un problema actual en la emergencia de resistencia entre los Gram positivos. Rev Med Hered. 2003; 14(4):195-203.

24. Voight R. Tratado de tecnología farmacéutica. Ed. Acribia. España; 1982.

Revisión de pares: Recibido: 15/08/2019 Aceptado: 11/10/2019 